\title{
Assessing the Role of Calcium-Induced Calcium Release in Short- Term Presynaptic Plasticity at Excitatory Central Synapses
}

\author{
Adam G. Carter, Kaspar E. Vogt, Kelly A. Foster, and Wade G. Regehr \\ Department of Neurobiology, Harvard Medical School, Boston, Massachusetts 02115
}

Recent evidence suggests that internal calcium stores and calcium-induced calcium release (CICR) provide an important source of calcium that drives short-term presynaptic plasticity at central synapses. Here we tested for the involvement of CICR in short-term presynaptic plasticity at six excitatory synapses in acute rat hippocampal and cerebellar brain slices. Depletion of internal calcium stores with thapsigargin and prevention of CICR with ryanodine have no effect on paired-pulse facilitation, delayed release of neurotransmitter, or calciumdependent recovery from depression. Fluorometric calcium measurements also show that these drugs have no effect on the residual calcium signal that underlies these forms of short-term presynaptic plasticity. Finally, although caffeine causes CICR in
Purkinje cell bodies and dendrites, it does not elicit CICR in parallel fiber inputs to these cells. Taken together, these results indicate that for the excitatory synapses studied here, internal calcium stores and CICR do not contribute to short-term presynaptic plasticity on the milliseconds-to-seconds time scale. Instead, this plasticity is driven by the residual calcium signal arising from calcium entry through voltage-gated calcium channels.

Key words: hippocampus; cerebellum; internal calcium stores; calcium-induced calcium release; ryanodine; thapsigargin; short-term presynaptic plasticity; presynaptic residual calcium
Short-term presynaptic plasticity on the milliseconds-to-seconds time scale allows synapses to continually modulate neurotransmitter release in response to presynaptic activity (Magleby, 1987; Zucker, 1989, 1999; Regehr and Stevens, 2001). Widespread forms of this plasticity include paired-pulse facilitation (PPF), $\mathrm{Ca}$-dependent recovery from depression (CDR) and delayed release of neurotransmitter (DR). PPF is prominent at synapses with a low initial probability of release and is characterized by increased release in response to sequential presynaptic action potentials (Katz and Miledi, 1968; Atluri and Regehr, 1996). In contrast, depression predominates at synapses with a high initial probability of release (Eccles et al., 1941; Feng, 1941), and early recovery from this depression is accelerated by CDR (Dittman and Regehr, 1998; Wang and Kaczmarek, 1998). Finally, DR is found at many synapses and represents an increase in neurotransmitter release for hundreds of milliseconds after presynaptic activity (Barrett and Stevens, 1972; Rahamimoff and Yaari, 1973; Zengel and Magleby, 1981; Zucker and Lara-Estrella, 1983; Cohen and Van der Kloot, 1986; Goda and Stevens, 1994; Van der Kloot and Molgo, 1994; Atluri and Regehr, 1998). Each of these short-term plasticities is driven by the residual $\mathrm{Ca}$ signal that persists in the terminal after presynaptic activity.

There is currently debate over the contribution of different $\mathrm{Ca}$ sources to the residual $\mathrm{Ca}$ signal and short-term presynaptic plasticity at excitatory central synapses. Voltage-gated Ca channels are one important source of Ca (Katz and Miledi, 1967; Dunlap et al., 1995; Mintz et al., 1995). Recent studies indicate

Received July 18, 2001; revised Oct. 4, 2001; accepted Oct. 10, 2001.

This work was supported by National Institutes of Health Grant R01-NS32405-01 to W.G.R. We thank Solange Brown, Dawn Blitz, John Decker, Alex Jackson, Anatol Kreitzer, and Matthew Xu-Friedman for comments on this manuscript.

Correspondence should be addressed to Wade G. Regehr, Department of Neurobiology, Harvard Medical School, 220 Longwood Avenue, Boston, MA 02115. E-mail: wade_regehr@hms.harvard.edu.

Copyright (C) 2001 Society for Neuroscience $\quad 0270-6474 / 01 / 220021-08 \$ 15.00 / 0$ that $\mathrm{Ca}$-induced $\mathrm{Ca}$ release (CICR) from internal $\mathrm{Ca}$ stores may be another important Ca source (Peng, 1996; Smith and Cunnane, 1996; Mothet et al., 1998; Narita et al., 1998; Krizaj et al., 1999; Llano et al., 2000; Narita et al., 2000; Emptage et al., 2001). $\mathrm{Ca}$ binding to ryanodine receptors located on internal $\mathrm{Ca}$ stores gates the opening of these receptors and triggers $\mathrm{Ca}$ release into the cytosol (Sitsapesan et al., 1995; Berridge, 1998). At peripheral synapses, extended trains of presynaptic activity can elicit CICR, which can in turn regulate neurotransmitter release (Peng, 1996; Smith and Cunnane, 1996; Narita et al., 1998, 2000). Presynaptic internal $\mathrm{Ca}$ stores and ryanodine receptors are present at some inhibitory central synapses, and CICR can influence spontaneous release rates and even elicit multivesicular release at inhibitory synapses onto cerebellar Purkinje cells (Llano et al., 2000). Although there have been few studies at excitatory central synapses, recent results at the associational-commissural (AC) synapse in the CA3 region of the hippocampus suggest that CICR contributes to both the residual Ca signal and PPF (Emptage et al., 2001). These results suggest that internal Ca stores and CICR may be an important $\mathrm{Ca}$ source contributing to short-term presynaptic plasticity at excitatory central synapses.

Here we survey the importance of internal $\mathrm{Ca}$ stores and CICR at multiple excitatory central synapses in acute hippocampal and cerebellar brain slices from young rats. Using caffeine to release $\mathrm{Ca}$ via ryanodine receptors, we show that significant CICR occurs in Purkinje cells but not at the presynaptic parallel fibers. Furthermore, using whole-cell voltage-clamp recordings and fluorometric $\mathrm{Ca}$ measurements, we show that depleting internal $\mathrm{Ca}$ stores or blocking ryanodine receptors has no effect on PPF, DR, $\mathrm{CDR}$, or the residual $\mathrm{Ca}$ signals that drive these plasticities. These results indicate that at central excitatory synapses, internal Ca stores and CICR do not generally make important contributions to either the residual $\mathrm{Ca}$ signal or short-term presynaptic plasticity. 


\section{MATERIALS AND METHODS}

Slices were cut from postnatal day 10-22 Sprague Dawley rats using standard procedures. Animals were anesthetized with halothane and decapitated, and their brains were rapidly removed and placed in ice-cold dissection solution equilibrated with $95 \% \mathrm{O}_{2}$ and $5 \% \mathrm{CO}_{2}$. For experiments using cerebellar slices, the dissection solution was the artificial CSF (ACSF; in mM: $125 \mathrm{NaCl}, 26 \mathrm{NaHCO}_{3}, 25$ Glucose, $2.5 \mathrm{KCl}, 1.25$ $\mathrm{NaH}_{2} \mathrm{PO}_{4}, 1 \mathrm{MgCl}_{2}$ and $2 \mathrm{CaCl}_{2}$ ). For experiments using hippocampal slices, the dissection solution contained (in $\mathrm{mM}$ ): $79 \mathrm{NaCl}$, 68 sucrose, 24 $\mathrm{NaHCO}_{3}, 23$ glucose, $2.3 \mathrm{KCl}, 1.14 \mathrm{NaH}_{2} \mathrm{PO}_{4}, 6.4 \mathrm{MgCl}_{2}$, and 0.46 $\mathrm{CaCl}_{2}$. Transverse cerebellar slices were prepared as described by Atluri and Regehr (1996); sagittal cerebellar slices were prepared as described by Kreitzer and Regehr (2000); and hippocampal slices were prepared as described by Vogt and Regehr (2001). After preparation, hippocampal slices were held at $32^{\circ} \mathrm{C}$ for $20 \mathrm{~min}$ and then transferred to ACSF $(2 \mathrm{~mm}$ $\mathrm{MgCl}_{2}$ and $3 \mathrm{~mm} \mathrm{CaCl}$ ). All slices were held at room temperature $\left(22-24^{\circ} \mathrm{C}\right)$ after $1 \mathrm{hr}$ at $32^{\circ} \mathrm{C}$. All experiments were performed at room temperature with $20 \mu \mathrm{M}$ bicuculline in the ACSF. The perfusion tubing and recording chamber were either replaced or washed with ethanol before and after experiments using ryanodine, thapsigargin or AM 251. Caffeine, ryanodine, thapsigargin, baclofen, and bicuculline were purchased from Sigma (St Louis, MO); CNQX, 2,3-dioxo-6-nitro-1,2,3,4tetrahydrobenzo[f]quinoxaline-7-sulfonamide (NBQX), and AM 251 were purchased from Tocris (Bristol, UK).

Electrophysiology. Whole-cell voltage-clamp recordings were obtained under visual control, using pipettes filled with an internal solution containing (in mM): $100 \mathrm{CsCl}, 35 \mathrm{CsF}, 10$ EGTA, 10 HEPES, and 0.1 ( \pm )-methoxyverapamil hydrochloride, $\mathrm{pH}$ 7.4. Pipette resistances were 2-3 M $\Omega$ for CA1 and CA3 pyramidal cells, 1-1.5 M $\Omega$ for Purkinje cells, and 2-3 M $\Omega$ for stellate cells. Access resistances were 5-15 M $\Omega$ for CA1 and $\mathrm{CA} 3$ pyramidal cells, 2-5 $\mathrm{M} \Omega$ for Purkinje cells, and 5-10 $\mathrm{M} \Omega$ for stellate cells. Access resistance and leak current were continually monitored, and experiments were discarded if either changed appreciably. Cells were voltage-clamped at $-60 \mathrm{mV}$ for CA1 and CA3 pyramidal cells, $-40 \mathrm{mV}$ for Purkinje cells, and $-70 \mathrm{mV}$ for stellate cells. Extracellular glass stimulus electrodes were filled with ACSF and placed in the afferent fiber tract. Stimulation of AC and mossy fiber (MF) synapses was as described by Vogt and Regehr (2001). Square pulses $(5-20 \mu \mathrm{A})$ of 0.2 msec duration were used to evoke EPSCs. In some cases, a second stimulus electrode was placed nearby to minimize stimulus artifacts. For experiments studying AC and MF synapses, $0.1 \mu \mathrm{M} \mathrm{NBQX}$ was used to prevent contributions from recurrent excitation (Salin et al., 1996), and we confirmed MF synapses using $10 \mu \mathrm{M}\left(2 S, 1^{\prime} S, 2^{\prime} S\right)$-2-(carboxycyclopropyl)glycine (Kamiya et al., 1996; Vogt and Regehr, 2001).

Presynaptic labeling and $\mathrm{Ca}$ measurements. Presynaptic fiber tracts were labeled with AM esters of either Magnesium Green or Oregon Green 488 BAPTA-1 (Molecular Probes, Eugene, OR), as described previously (Regehr and Tank, 1991; Regehr and Atluri, 1995). AC and MF fiber tracts were labeled as described by Vogt and Regehr (2001), parallel fiber (PF) tracts were labeled as described by Regehr and Atluri (1995), and individual climbing fibers were labeled using in vivo injection of Fluo-4 Dextran (Molecular Probes) as described by Kreitzer et al. (2000). Slices were placed on an upright microscope (Olympus Optical, Tokyo, Japan; or Zeiss, Thornwood, NY) and visualized with either a $40 \times$ or $60 \times$ water immersion objective. Stimulus electrodes were placed as for electrophysiology experiments. A small region of labeled fibers was illuminated, and fluorescence signals were measured with a photodiode (Regehr and Atluri, 1995; Kreitzer et al., 2000; Vogt and Regehr, 2001). The Magnesium Green, Oregon Green 488 BAPTA-1, and Fluo-4 Dextran filter set was 450-490 excitation, 510 dichroic, and 520 emission. With increasing Ca concentrations, Magnesium Green, Oregon Green 488 BAPTA-1, and Fluo-4 Dextran fluorescence increases.

Postsynaptic labeling and Ca measurements. Whole-cell voltage-clamp recordings of Purkinje cells were obtained using pipettes filled with an internal solution containing (in $\mathrm{mm}$ ): $130 \mathrm{CsGlu}, 20 \mathrm{CsCl}, 2 \mathrm{MgCl}_{2}, 0.2$ EGTA, 10 HEPES, $4 \mathrm{Na}_{2}$ ATP, 0.4 NaGTP, and 0.2 Oregon Green 488 BAPTA-1, pH 7.4. Pipette resistance was 2-3 M 2 ; access resistance was 5-15 M $\Omega$; and Purkinje cells were voltage-clamped at $-60 \mathrm{mV}$. After obtaining whole-cell recordings, Purkinje cells were allowed to fill with $200 \mu \mathrm{M}$ Oregon Green 488 BAPTA-1 for 5-10 min. Fluorescence signals from the Purkinje cell soma and proximal dendrites were measured with a photodiode. In some experiments, Purkinje cells were depolarized between trials to elicit action potentials that replenished internal $\mathrm{Ca}$ stores and allowed stable caffeine-evoked CICR. During these experiments, $10 \mu \mathrm{M}$ NBQX and $1 \mu \mathrm{M}$ TTX were present in the ACSF.
Focal application of drugs. Drugs were loaded into glass micropipettes with a tip diameter of 2-5 $\mu \mathrm{m}$. Pipettes were attached to a pneumatic injection system (PV820; World Precision Instruments, Sarasota, FL), and pressure pulses at $3-5$ psi for $5 \mathrm{sec}$ duration were used to eject drugs into the ACSF. The system was calibrated with a solution containing fast green to detect leakage of pipette solution or back-filling of pipettes with ACSF. Pipettes were placed $\sim 10-20 \mu \mathrm{m}$ above the slice and $\sim 10-20 \mu \mathrm{m}$ upstream from the recording site. Although pipettes contained high concentrations of drugs, the concentration reaching the cell was considerably diluted.

Data acquisition and analysis. Outputs from both the photodiode and the AxoPatch $200 \mathrm{~A}$ or $200 \mathrm{~B}$ amplifiers were digitized with a 16-bit digital-to-analog converter (Instrutech, Port Washington, NY), Pulse Control software (Herrington and Bookman, 1995), and a Macintosh computer (Apple, Cupertino, CA). Analysis was done on- and off-line using Igor Pro software (Wavemetrics, Lake Oswego, OR). Whole-cell recordings were filtered at $2-5 \mathrm{kHz}$ with an eight-pole Bessel filter. Photodiode recordings of stimulus-evoked fluorescence signals were digitally filtered at 500 or $200 \mathrm{~Hz}$ with a four-pole Bessel filter. Photodiode recordings of puff-evoked fluorescence signals in Figure 1 were digitally filtered at $10 \mathrm{~Hz}$ with a four-pole Bessel filter. Data are reported as average \pm SEM.

\section{RESULTS}

We examined the role of internal calcium stores and CICR in short-term presynaptic plasticity and presynaptic residual calcium signals at six excitatory central synapses in acute hippocampal and cerebellar brain slices of young rats. These synapses were studied because they exhibit many forms of short-term presynaptic plasticity and are amenable to presynaptic $\mathrm{Ca}$ measurements. Internal Ca stores were depleted with thapsigargin (Treiman et al., 1998), which inhibits the Ca-ATPases that load these stores. CICR was blocked with high concentrations of ryanodine (Sitsapesan et al., 1995).

\section{Prominent caffeine-evoked CICR at Purkinje cells}

We assessed the efficacy of ryanodine and thapsigargin by testing their ability to disrupt caffeine-evoked Ca signals in Purkinje cells (Llano et al., 1994; Kano et al., 1995). Purkinje cells were loaded with the Ca indicator Oregon Green 488 BAPTA-1, and fluorescence signals were monitored from the soma and proximal dendrites. Pressure application of caffeine from a nearby extracellular micropipette led to CICR in Purkinje cells, which caused a Ca-evoked fluorescence increase (Fig. 1), measured as a change in fluorescence over background fluorescence $(\Delta F / F)$ signal. After obtaining a stable $\Delta F / F$ signal in response to caffeine application at 2 min intervals, we washed ryanodine or thapsigargin into the bath. For the representative experiments shown in Figure 1 , the peak $\Delta F / F$ signal was reduced to $11.3 \%$ of control for $10 \mu \mathrm{M}$ ryanodine (Fig. $1 A$ ) and $10.1 \%$ of control for $10 \mu \mathrm{M}$ thapsigargin (Fig. $1 B$ ). In general, the peak $\Delta F / F$ signal was reduced to $7.5 \pm 5.8 \%$ of control for $100 \mu \mathrm{M}$ ryanodine $(n=3)$, $9.4 \pm 4.7 \%$ of control for $10 \mu \mathrm{M}$ ryanodine (Fig. $1 A ; n=5$ ), and $-1.4 \pm 3.6 \%$ of control for $10 \mu \mathrm{M}$ thapsigargin (Fig. $1 B ; n=6$ ). In these experiments, a small $\Delta F / F$ signal often persisted even after prolonged exposure to ryanodine or thapsigargin. This signal may reflect residual CICR not blocked by ryanodine or thapsigargin, or may reflect a mechanical artifact that can also be observed with puff application of external solution alone. High concentrations of caffeine can also directly affect the properties of $\mathrm{Ca}$ indicators via nonspecific, hydrophobic interactions with the fluorophore (Muschol et al., 1999), and this could also contribute to the remaining $\Delta F / F$ signal. These experiments demonstrate that either ryanodine or thapsigargin effectively prevents CICR in Purkinje cells. 

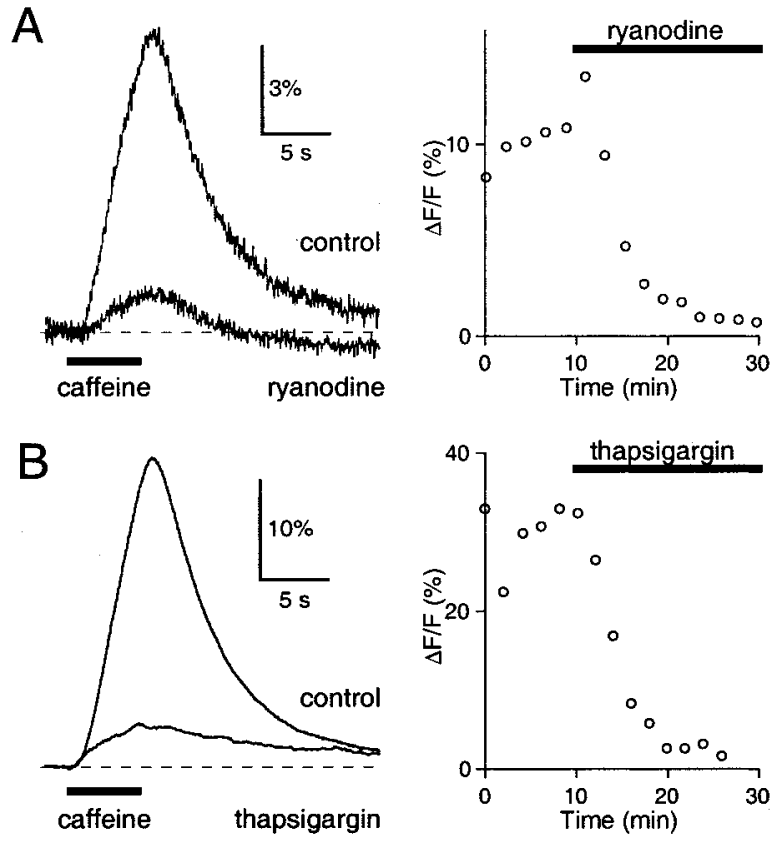

Figure 1. Ryanodine and thapsigargin abolish caffeine-evoked CICR in Purkinje cells. A Purkinje cell was filled with $200 \mu \mathrm{M}$ Oregon Green 488 BAPTA-1 via a whole-cell recording pipette, and $40 \mathrm{~mm}$ caffeine was applied using a $5 \mathrm{sec}$ pressure puff from a nearby micropipette. Fluorescence measurements were restricted to a small area that included the Purkinje cell soma and proximal dendrites. $A$, In control conditions, a $\Delta F / F$ signal was recorded (left) in response to caffeine application (solid bar). Bath application of $10 \mu \mathrm{M}$ ryanodine abolished this $\Delta F / F$ signal. The time course is shown on the right, with the solid bar indicating ryanodine application. $B$, Similar results were found for bath application of $10 \mu \mathrm{M}$ thapsigargin. Representative traces are averages of four or five trials.

\section{Lack of caffeine-evoked CICR at parallel fibers}

We next used pressure application of caffeine to directly test for CICR at the parallel fiber presynaptic inputs to Purkinje cells (Fig. 2). Parallel fibers were loaded with the high-affinity $\mathrm{Ca}$ indicator Oregon Green 488 BAPTA-1 AM. Fluorescence signals were monitored from a region of parallel fibers $300-500 \mu \mathrm{m}$ from the loading site, and parallel fibers were stimulated with an extracellular electrode. Drugs were pressure-applied from an extracellular micropipette near the recording site.

The efficacy of pressure application was tested with baclofen, which inhibits presynaptic $\mathrm{Ca}$ channels by activating $\mathrm{GABA}_{\mathrm{B}}$ receptors (Mintz and Bean, 1993; Dittman and Regehr, 1996). As shown in a representative experiment, baclofen $(500 \mu \mathrm{M})$ greatly reduced the test stimulus-evoked $\Delta F / F$ signal (Fig. $2 A$ ). In five such experiments, baclofen reduced the peak of this signal to $52.9 \pm 5.6 \%$ of control.

In contrast, caffeine had small effects on the $\Delta F / F$ signals. Caffeine $(40 \mathrm{~mm})$ produced a slow $\Delta F / F$ signal that was much smaller than the stimulus-evoked $\Delta F / F$ signal (Fig. $2 B$ ) and was often in an opposite direction from the mechanical artifact. In 11 such experiments, the slow $\Delta F / F$ signal was $13.9 \pm 2.5 \%$ of the control stimulus-evoked $\Delta F / F$ signal. Caffeine also produced a slight increase in the test stimulus-evoked $\Delta F / F$ signal (Fig. $2 B$ ). In 11 such experiments, caffeine increased the peak of this signal by $12.3 \pm 3.4 \%$.

Unlike the caffeine-evoked $\Delta F / F$ signal seen in Purkinje cells (Fig. 1), bath application of ryanodine or thapsigargin did not affect the $\Delta F / F$ signals seen in parallel fibers (Fig. $2 B$ ). The slow
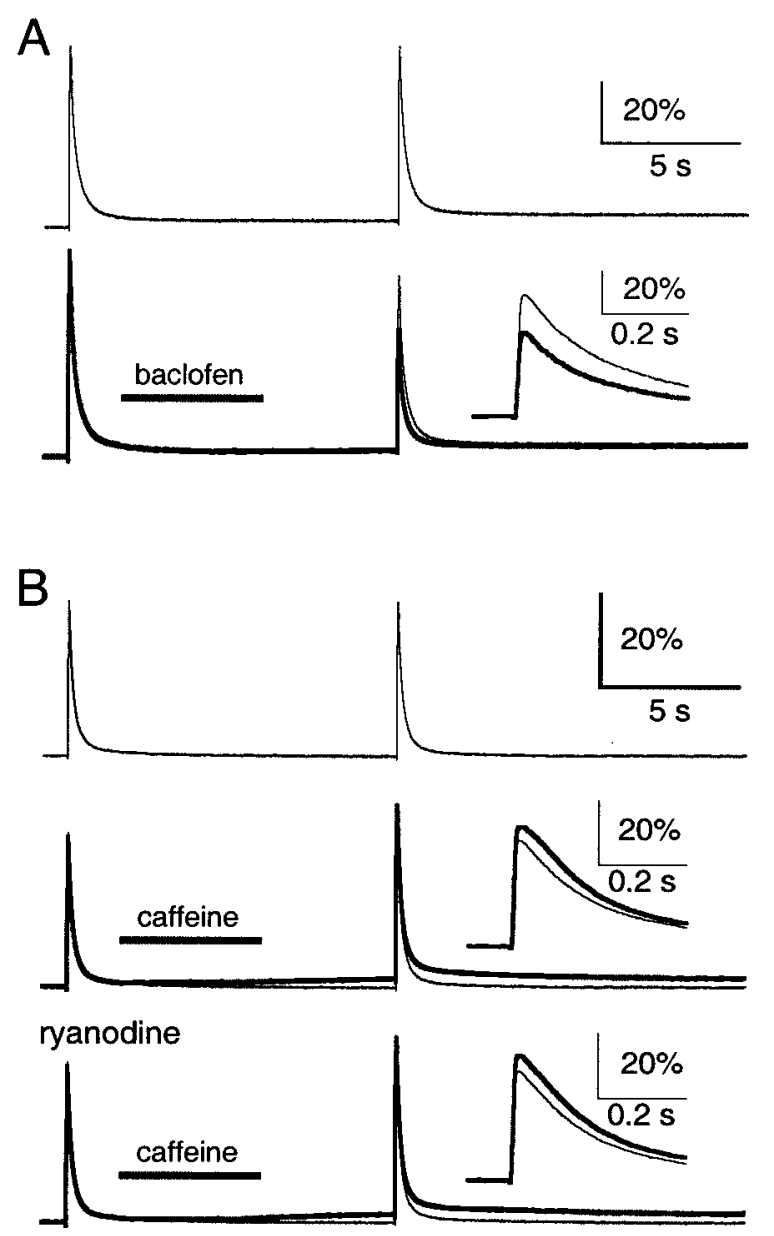

Figure 2. Lack of caffeine-evoked CICR at the parallel fibers. Parallel fibers were filled with Oregon Green 488 BAPTA-1 AM. In each trial, parallel fibers were stimulated with a control and test stimulus separated by $10 \mathrm{sec} . A, \Delta F / F$ signals in the absence of drug application (top, bottom, light traces) and with puff application of $500 \mu \mathrm{M}$ baclofen (bottom, bold trace). Inset, Test $\Delta F / F$ signals with baclofen (bold trace) or without (light trace) on an expanded time scale. $B, \Delta F / F$ signals in the absence of drug application (top, middle, bottom, light trace) and with puff application of 40 $\mathrm{mm}$ caffeine, in the absence (middle, bold trace) and presence (bottom, bold trace) of $10 \mu \mathrm{M}$ ryanodine. Insets, Test $\Delta F / F$ signals with caffeine (bold trace) or without (light trace) on an expanded time scale. Representative traces are averages of three to five trials. For insets in $B$, the slow $\Delta F / F$ signal has been subtracted.

$\Delta F / F$ signal was still $11.9 \pm 3.0 \%(n=3)$ of the control stimulusevoked $\Delta F / F$ signal in $10 \mu \mathrm{M}$ ryanodine and $11.9 \pm 4.7 \%(n=5)$ of this signal in $10 \mu \mathrm{M}$ thapsigargin. Moreover, caffeine continued to increase the peak of the test stimulus-evoked $\Delta F / F$ signal by $13.9 \pm 4.5 \%(n=3)$ in ryanodine and $9.5 \pm 3.2 \%(n=5)$ in thapsigargin. The slow $\Delta F / F$ signal and the small increase in the test stimulus-evoked $\Delta F / F$ signal thus likely reflect a direct interaction of caffeine with the Ca indicator (Muschol et al., 1999). These results suggest that CICR may not be important for presynaptic $\mathrm{Ca}$ signaling at parallel fiber synapses. We thus proceeded to test the role of $\mathrm{Ca}$ stores and CICR on short-term presynaptic plasticity and the presynaptic residual $\mathrm{Ca}$ signal at this and other excitatory central synapses.

\section{Paired-pulse facilitation}

We next used ryanodine and thapsigargin to test for the involvement of internal Ca stores in PPF. These studies were conducted 
at 4 different excitatory synapses: the cerebellar parallel fiber to Purkinje cell $(\mathrm{PF} \rightarrow \mathrm{PC})$ synapse, the hippocampal AC synapse between CA3 pyramidal cells, the hippocampal MF synapse between dentate gyrus granule cells and CA3 pyramidal cells, and the hippocampal Schaffer collateral (SC) synapse between CA3 and CA1 pyramidal cells. EPSCs were monitored with whole-cell voltage-clamp recordings. Synaptic inputs were stimulated with pairs of pulses separated by 25 or $75 \mathrm{msec}$. PPF is defined as $A 2 / A 1$, where $A 1$ and $A 2$ are the amplitudes of the EPSCs evoked by the first and second pulses, respectively. PPF25 and PPF75 indicate the PPF amplitude for the two interpulse intervals. PPF25 and PPF75 were prominent at all these synapses, with values of $2.67 \pm 0.14$ and $2.09 \pm 0.09(n=8)$ at the $\mathrm{PF} \rightarrow \mathrm{PC}$ synapse, $2.08 \pm 0.11$ and $1.88 \pm 0.09(n=12)$ at the AC synapse, $3.48 \pm 0.39$ and $2.53 \pm 0.34(n=4)$ at the MF synapse, and $1.92 \pm 0.27$ and $1.66 \pm 0.14(n=5)$ at the SC synapse.

Neither thapsigargin nor ryanodine affected PPF at these synapses. A representative experiment is shown for the $\mathrm{PF} \rightarrow \mathrm{PC}$ synapse in Figure $3 A$, in which thapsigargin did not affect the EPSC, PPF25, or PPF75. The percent changes for PPF25 and PPF75 relative to that seen in control conditions were $-4.2 \pm 5.1$ and $4.9 \pm 5.1 \%$, respectively, for $10 \mu \mathrm{M}$ thapsigargin $(n=4)$, $-2.9 \pm 6.3$ and $2.0 \pm 4.8 \%$ for $100 \mu \mathrm{M}$ ryanodine $(n=4)$, and $-3.5 \pm 3.7$ and $3.4 \pm 3.3 \%$ for pooled thapsigargin and ryanodine experiments $(n=8)$. Hereafter, data from thapsigargin and ryanodine experiments are pooled. As shown in representative experiments, similar results were obtained using $10 \mu \mathrm{M}$ ryanodine at the AC (Fig. 3B) and MF (Fig. 3C) synapses, and $100 \mu \mathrm{M}$ ryanodine at the $\mathrm{SC}$ synapse (Fig. $3 D$ ). The overall percent changes for PPF25 and PPF75 in thapsigargin or ryanodine were $2.7 \pm 4.3$ and $4.7 \pm 5.0 \%(n=12)$ at the AC synapse, $-9.4 \pm 13.6$ and $11.9 \pm 11.4 \%(n=4)$ at the MF synapse, and $-0.1 \pm 19.0$ and $2.5 \pm 11.1 \%(n=5)$ at the SC synapse. In some experiments, although PPF25 and PPF75 remained unchanged, $100 \mu \mathrm{M}$ ryanodine decreased the peak EPSC. This may reflect a decrease in fiber excitability, because the prespike amplitude was also reduced by this high concentration of ryanodine (data not shown). Overall, these results indicate that internal $\mathrm{Ca}$ stores and CICR are not involved in PPF at these four synapses.

Recent results demonstrate that presynaptic $\mathrm{Ca}$ signals and $\mathrm{PPF}$ at the $\mathrm{PF} \rightarrow \mathrm{PC}$ synapse can be modulated by retrograde signaling via Ca-dependent cannabinoid release from Purkinje cells (Kreitzer and Regehr, 2001). We tested the possibility that disrupting postsynaptic internal $\mathrm{Ca}$ stores in Purkinje cells can modify retrograde signaling to occlude any effects of disrupting presynaptic internal Ca stores. In the presence of $10 \mu \mathrm{M} \mathrm{AM} \mathrm{251,}$ an antagonist of $\mathrm{CB} 1$ receptors that blocks retrograde signaling, the percent changes for PPF25 and PPF75 in thapsigargin were $-5.3 \pm 5.0$ and $-8.0 \pm 1.1 \%(n=3)$, indicating that retrograde signaling does not occlude any presynaptic effect of thapsigargin.

\section{Delayed release}

DR is the continued release of neurotransmitter for hundreds of milliseconds after a presynaptic action potential. This phenomenon is driven by the residual $\mathrm{Ca}$ signal and is eliminated by chelators of presynaptic Ca (Cummings et al., 1996; Atluri and Regehr, 1998). The effects of ryanodine and thapsigargin on DR were assessed at the parallel fiber to stellate cell synapse. We recorded from stellate cells using whole-cell voltage clamp and examined synaptic inputs after a single pulse to the parallel fibers (Atluri and Regehr, 1998). As shown in a representative experiment, spontaneous quantal events before stimulation are rare in
A
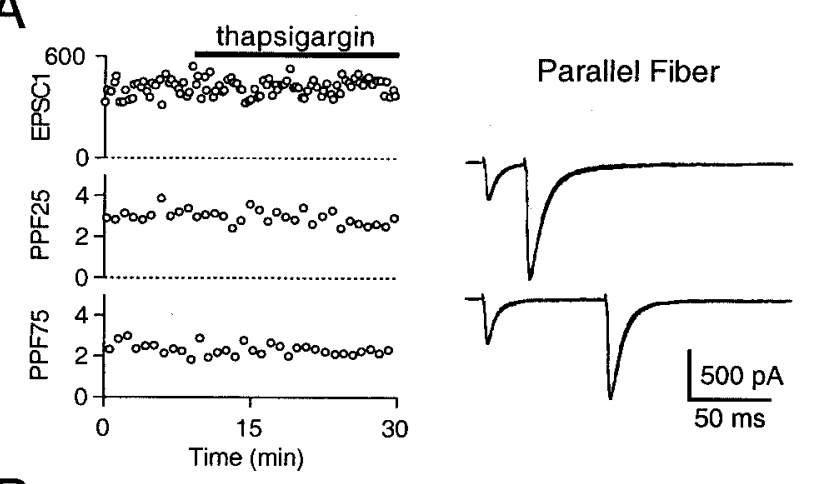

B
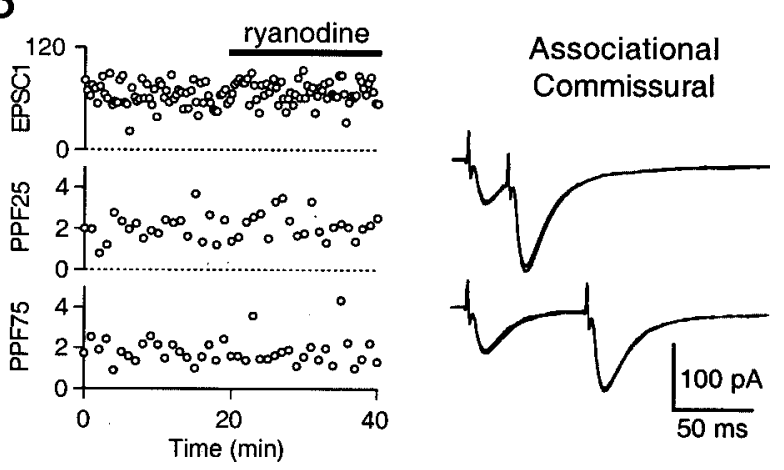

Q
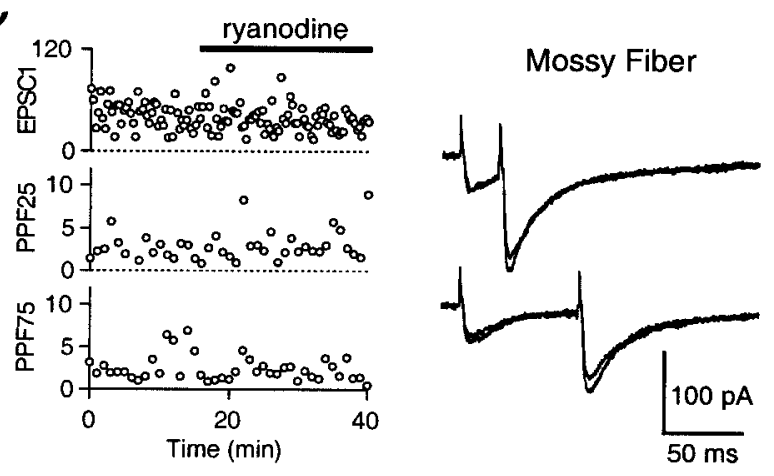

D

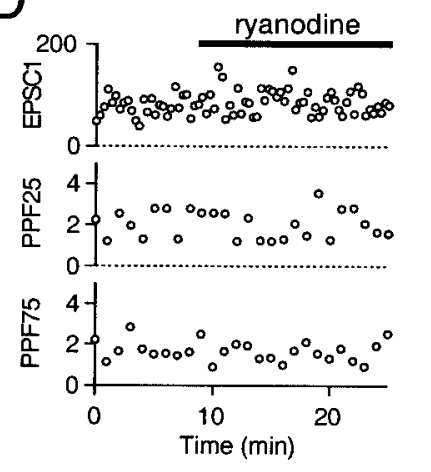

Schaffer Collateral

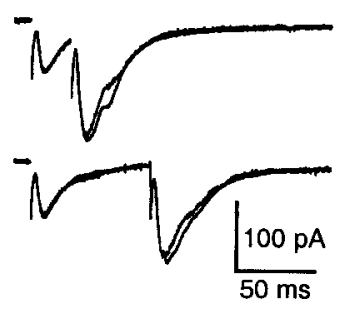

Figure 3. Disrupting CICR has no effect on paired-pulse facilitation at four excitatory synapses. $A$, At the $\mathrm{PF} \rightarrow \mathrm{PC}$ synapse, peak EPSC (EPSC1, picoamperes), PPF25, and PPF75 remain unchanged after bath application of $10 \mu \mathrm{M}$ thapsigargin (solid bar). Representative traces (right) are superimposed averages of five trials before and after thapsigargin application. Similar results were found using $10 \mu \mathrm{M}$ ryanodine at the $\mathrm{AC}(B)$ and MF $(C)$ synapses, and $100 \mu \mathrm{M}$ ryanodine at the SC synapse $(D)$. 


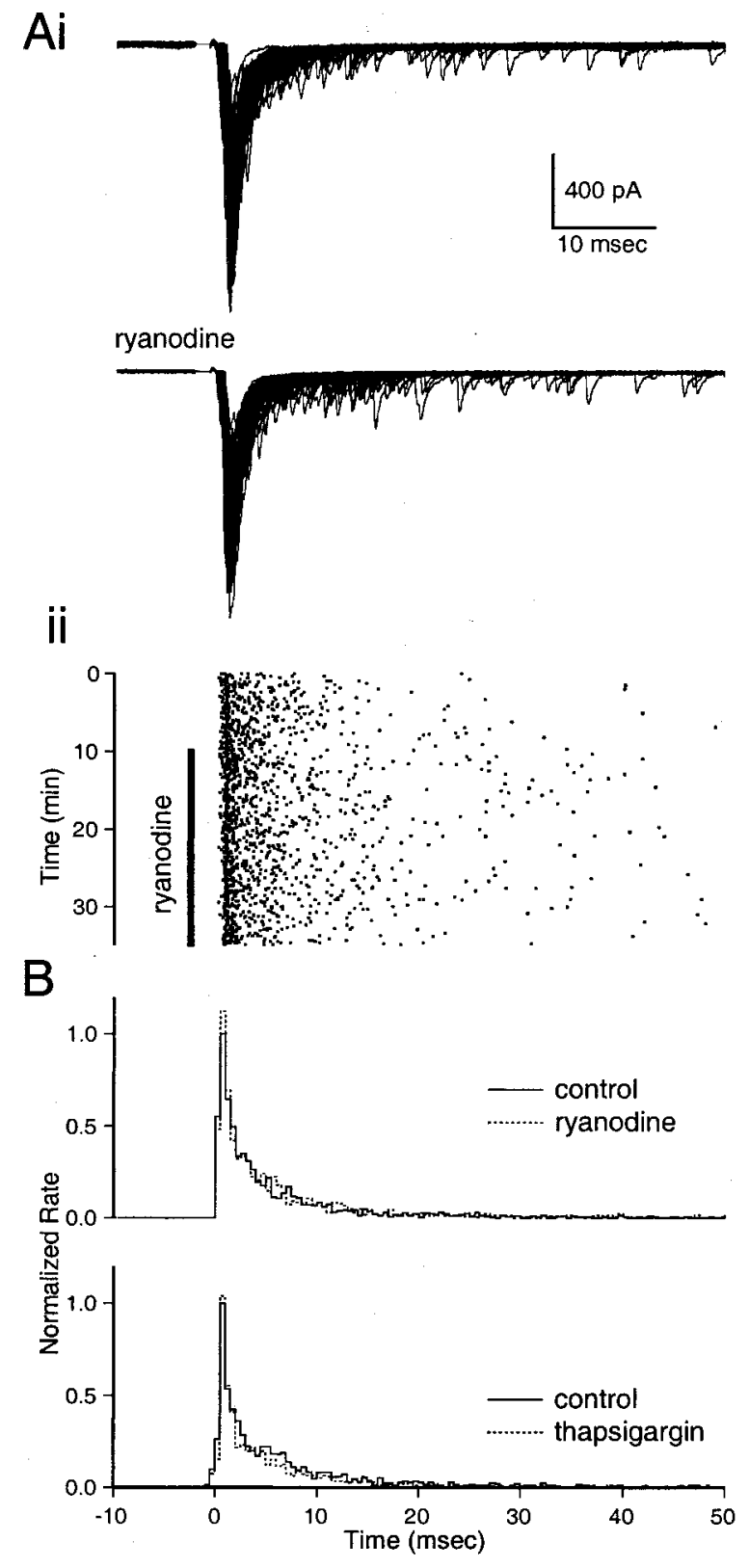

Figure 4. Disrupting CICR has no effect on delayed release at the parallel fiber to stellate cell synapse. $A i$, Seventy consecutive traces before (top) and after (bottom) bath application of $10 \mu \mathrm{M}$ ryanodine. Aii, Raster plot of quantal events, with the vertical bar indicating the time of ryanodine application. $B$, Average PSTH plots of quantal events before (solid line) and after (dashed line) $10 \mu \mathrm{M}$ ryanodine $(B$, top; $n=4)$ or $10 \mu \mathrm{M}$ thapsigargin $(B$, bottom; $n=4)$. PSTH plots for each experiment were made for 10 min periods in both control conditions and after 10 min drug application. These PSTH plots were then normalized with respect to the peak rate in control conditions. Normalized PSTH plots from the different experiments were then averaged.

these cells, but stimulation produces prominent DR (Fig. 4Ai, top). After recording stable synaptic inputs for $10 \mathrm{~min}, 10 \mu \mathrm{M}$ ryanodine was bath-applied for $25 \mathrm{~min}$. The prominent DR was still apparent after prolonged wash-in of ryanodine (Fig. 4Ai, bottom). This is illustrated using a raster plot of quantal events recorded throughout the experiment (Fig. 4Aii). In general, we found that DR was unchanged by either ryanodine $(10 \mu \mathrm{M}, n=4)$ or thapsigargin $(10 \mu \mathrm{M}, n=4)$. This is shown using average

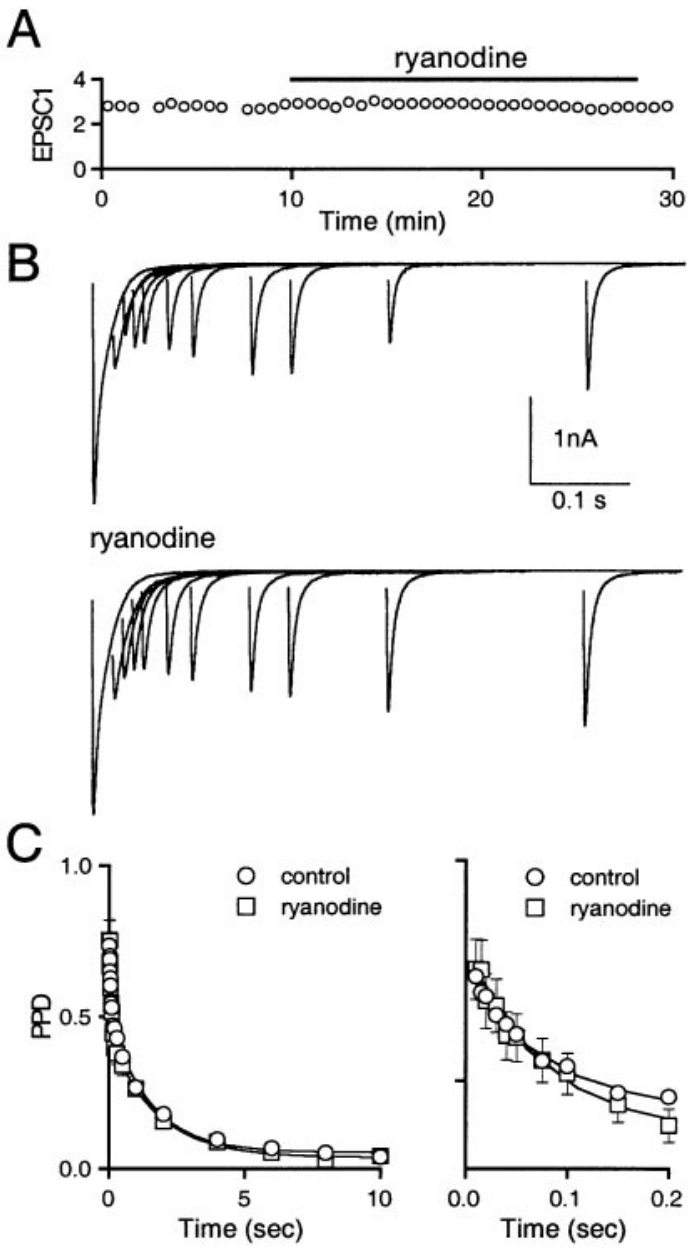

Figure 5. Disrupting CICR has no effect on calcium-dependent recovery from depression at the climbing fiber to Purkinje cell synapse. $A$, Initial EPSC amplitude (EPSC1, nanoamperes) remains unchanged after bath application of $100 \mu \mathrm{M}$ ryanodine (solid bar). B, Representative traces before (top) and after (bottom) bath application of ryanodine. $C$, PPD curves showing recovery from depression over $10 \mathrm{sec}$, with the first 200 msec expanded on the right. Representative traces in $B$ are averages of two trials. PPD curves are averages \pm SEM from 17 (control) or 5 (ryanodine) experiments.

poststimulus time histogram (PSTH) plots of quantal event frequency compiled $10 \mathrm{~min}$ before and after complete wash-in of ryanodine (Fig. 4B, top) or thapsigargin (Fig. 4B, bottom). These results indicate that CICR does not make a prominent contribution to the Ca signal that drives DR at this synapse.

\section{Ca-dependent recovery from depression}

The climbing fiber to Purkinje cell $(\mathrm{CF} \rightarrow \mathrm{PC})$ synapse exhibits profound paired-pulse depression (PPD), characterized by decreased release in response to sequential presynaptic action potentials (Eccles et al., 1966; Dittman and Regehr, 1998; Hashimoto and Kano, 1998; Silver et al., 1998). The rapid phase of recovery from depression is driven by increases in presynaptic Ca, and is known as CDR (Dittman and Regehr, 1998; Wang and Kaczmarek, 1998). Ryanodine was used to test for the importance of CICR in CDR. We recorded from Purkinje cells using wholecell voltage clamp and stimulated climbing fibers with pairs of pulses separated by varying interstimulus intervals. As shown in a representative experiment, $100 \mu \mathrm{M}$ ryanodine had no effect on the initial EPSC amplitude (Fig. 5A) or the recovery from depres- 
sion (Fig. 5B). PPD is defined as $(A 1-A 2) / A 1$, and curves of PPD at different interstimulus intervals indicate the time course of recovery from depression (Fig. $5 C$ ). We fit these curves with a function of the form $A_{\mathrm{o}}+A_{1} \exp \left(-t / \tau_{1}\right)+A_{2} \exp \left(-t / \tau_{2}\right)$, with $A_{1}$ and $\tau_{1}$ corresponding to the CDR component. In control conditions the parameters $\left\{A_{\mathrm{o}}, A_{1}, \tau_{1}, A_{2}\right.$, and $\left.\tau_{2}\right\}$ were $\{7 \%, 35 \%, 57$ msec, $57 \%$, and $1.5 \mathrm{sec}\}(n=17)$, and in the presence of ryanodine they were $\{4 \%, 45 \%, 65 \mathrm{msec}, 50 \%$, and $1.7 \mathrm{sec}\}(n=$ $5)$. For three cells, PPD curves were obtained both in control conditions $\{4 \%, 46 \%, 59 \mathrm{msec}, 49 \%$, and $1.9 \mathrm{sec}\}$ and in the presence of ryanodine $\{5 \%, 47 \%, 67 \mathrm{msec}, 48 \%$, and $1.6 \mathrm{sec}\}$. The similarity of the amplitude and time course of the fast component of recovery from depression in ryanodine and control conditions suggests that CICR does not contribute to CDR at this synapse.

\section{Presynaptic residual Ca signal}

We next used ryanodine and thapsigargin to test directly for the involvement of CICR in shaping the residual Ca signal at PF, AC, $\mathrm{MF}$, and $\mathrm{CF}$ synapses. For these experiments, presynaptic fibers were labeled with low-affinity $\mathrm{Ca}$ indicators, which provide an accurate means of detecting changes in the amplitude and time course of residual $\mathrm{Ca}$. Presynaptic fibers were activated with either single pulses or pairs of pulses separated by 25 or $75 \mathrm{msec}$, and the resulting $\Delta F / F$ signals were detected as described previously (Regehr and Atluri, 1995). A representative experiment for the effect of ryanodine on the residual $\mathrm{Ca}$ signal is shown for the $\mathrm{PF}$ synapse in Figure $6 A$. After recording stable peak $\Delta F / F$ responses for $10 \mathrm{~min}$, ryanodine was bath-applied for $20 \mathrm{~min}$. Ryanodine had no effect on either the peak or half-decay time of the $\Delta F / F$ signal (Fig. $6 A$ ). In general, the residual Ca signal at the PF synapse was unchanged by either ryanodine $(100 \mu \mathrm{M}, n=2 ; 10$ $\mu \mathrm{M}, n=5)$ or thapsigargin $(10 \mu \mathrm{M}, n=3)$. The overall percent changes for peak and half-decay time of the first $\Delta F / F$ signal in ryanodine or thapsigargin relative to that seen in control conditions were $5.2 \pm 3.5$ and $-5.2 \pm 2.4 \%(n=10)$. The lack of effect of ryanodine or thapsigargin on $\mathrm{Ca}$ transients in parallel fibers evoked by single stimuli is consistent with the results of Sabatini and Regehr (1995). As shown for representative experiments, similar results were obtained using $10 \mu \mathrm{M}$ ryanodine at the AC synapse (Fig. 6B), and $100 \mu \mathrm{M}$ ryanodine at the MF (Fig. $6 C$ ) and CF (Fig. 6D) synapses. The overall percent changes for peak and half-decay time of the first $\Delta F / F$ signals in ryanodine or thapsigargin were $-1.6 \pm 4.4$ and $-0.2 \pm 3.2 \%(n=3)$ at the $\mathrm{AC}$ synapse, $0.8 \pm 1.8$ and $-6.1 \pm 2.7 \%(n=3)$ at the MF synapse, and $-7.1 \pm 1.9$ and $14.3 \pm 6.3 \%(n=5)$ at the CF synapse. These results indicate that $\mathrm{CICR}$ does not determine the size or time course of the residual Ca signal.

\section{DISCUSSION}

Our primary finding is that internal Ca stores and CICR do not contribute to short-term presynaptic plasticity or the residual $\mathrm{Ca}$ signal on the milliseconds-to-seconds time scale at a number of excitatory central synapses. Furthermore, although prominent caffeine-evoked CICR is present in Purkinje cells, it is not found in the parallel fiber synaptic inputs onto those cells. These results suggest that $\mathrm{Ca}$ influx through voltage-gated $\mathrm{Ca}$ channels generates the residual $\mathrm{Ca}$ signal that shapes short-term presynaptic plasticity at excitatory central synapses.
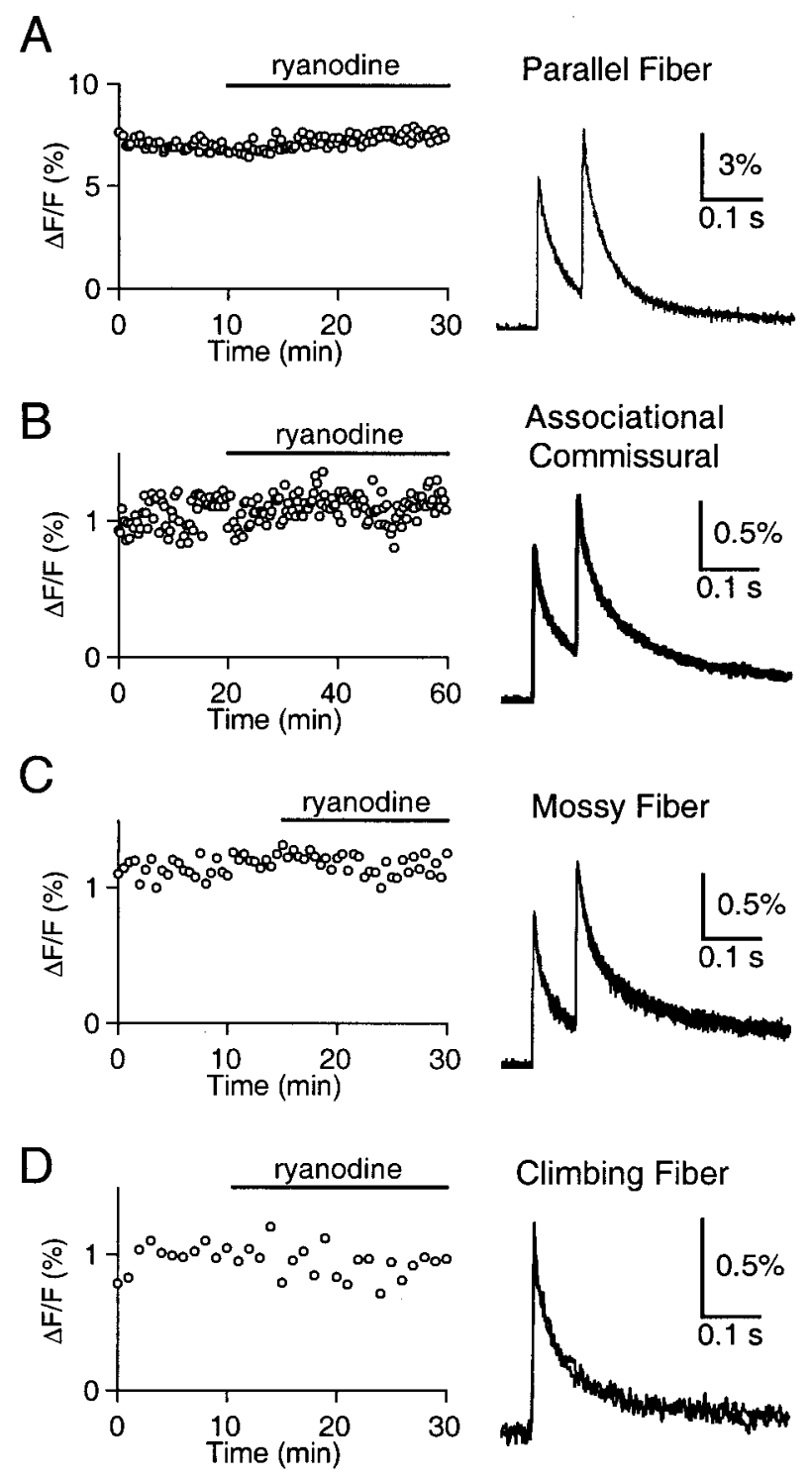

Figure 6. Disrupting CICR has no effect on the residual calcium signal at four excitatory synapses. $A$, At the PF synapse, peak $\Delta F / F$ signal (left) remains unchanged after bath application of $10 \mu \mathrm{M}$ ryanodine (solid bar). Representative traces (right) are superimposed averages of five trials before and after ryanodine application. Similar results were found using $10 \mu \mathrm{M}$ ryanodine at the $\mathrm{AC}$ synapse $(B)$, and $100 \mu \mathrm{M}$ ryanodine at the $\mathrm{MF}$ $(C)$ and $\mathrm{CF}(D)$ synapses.

\section{Role of internal Ca stores in presynaptic Ca signaling and short-term presynaptic plasticity}

Previous studies provide insight into the source of $\mathrm{Ca}$ that gives rise to the presynaptic residual $\mathrm{Ca}$ signal. After a single stimulus, $\mathrm{Ca}$ influx coincident with the presynaptic action potential is confined to a period of several hundred microseconds (Sabatini and Regehr, 1998). This rapid influx can generate a large peak Ca signal, which equilibrates through the presynaptic terminal and gives rise to the residual $\mathrm{Ca}$ signal. The dependence of this residual $\mathrm{Ca}$ signal on the concentrations of external $\mathrm{Ca}$ and cadmium, as well as the additivity of the block by subtype-specific Ca channel toxins (Mintz et al., 1995), also suggests that Ca influx through voltage-gated $\mathrm{Ca}$ channels is sufficient to produce the residual $\mathrm{Ca}$ signal that drives short-term presynaptic plasticity.

Although previous studies implicate a role for internal $\mathrm{Ca}$ 
stores in some forms of synaptic plasticity, most studies suggest that CICR does not contribute to short-term presynaptic plasticity at central excitatory synapses. At peripheral synapses, internal $\mathrm{Ca}$ stores and CICR have, in some cases, been shown to shape the residual Ca signal and presynaptic plasticity (Peng, 1996; Smith and Cunnane, 1996; Narita et al., 1998, 2000). However, this contribution often takes place during trains of presynaptic activity, and short-term presynaptic plasticities such as PPF may remain unaltered (Narita et al., 2000). At central excitatory synapses, CICR in dendrites has been shown to contribute to postsynaptic responses and long-term postsynaptic plasticity (Obenaus et al., 1989; Alford et al., 1993; Wang et al., 1997; Emptage et al., 1999; Futatsugi et al., 1999). In contrast, evidence for the importance of CICR in presynaptic terminals for longterm plasticity has been indirect (Reyes and Stanton, 1996; ReyesHarde et al., 1999) or absent. Furthermore, drugs that disrupt CICR have generally not been found to affect baseline synaptic strength or short-term presynaptic plasticity (Reyes and Stanton, 1996; Emptage et al., 1999; Reyes-Harde et al., 1999).

Our results contrast with a study suggesting an important role for CICR in mediating presynaptic Ca transients and PPF at the AC synapse (Emptage et al., 2001). These conflicting results may reflect several differences in our experimental conditions. Emptage at al. (2001) used organotypic slices, measured PPF with whole-cell current-clamp recordings, and measured $\mathrm{Ca}$ transients from individual boutons with single-photon confocal recordings. We used acute brain slices, which can have different properties from organotypic slices. This is illustrated by the differences in the magnitude of PPF in these preparations (the percent increase in PPF at $75 \mathrm{msec}$ is $88 \%$ in acute slices, compared with $33 \%$ in organotypic slices). We also used whole-cell voltage-clamp recordings with low concentrations of NBQX to limit recurrent excitatory connections in the CA3 region. Finally, we measured the residual $\mathrm{Ca}$ signal from populations of presynaptic fibers and used low-intensity illumination to improve stability.

\section{Complications associated with studying internal Ca stores}

A number of complications can arise when studying internal $\mathrm{Ca}$ stores and CICR. First, although caffeine is often used to elicit CICR, it can directly interact with the fluorescence properties of $\mathrm{Ca}$ indicators (Muschol et al., 1999). This artifact is difficult to correct and can lead to false-positive results. Second, ryanodine is used to block CICR but at high concentrations may reduce EPSC size via a decrease in fiber excitability. Third, bath application of drugs used to study CICR may affect internal Ca stores in glia or postsynaptic neurons (Castonguay and Robitaille, 2001). Glia can release ATP or glutamate that can affect neurotransmitter release by activating presynaptic receptors (Araque et al., 1998, 2001; Haydon, 2001). Ca elevation in postsynaptic cells can evoke the release of retrograde messengers that can inhibit neurotransmitter release from presynaptic terminals (Kreitzer and Regehr, 2001; Wilson and Nicoll, 2001).

\section{Potential role for internal Ca stores in presynaptic function and plasticity}

Although our results indicate that CICR does not contribute to PPF, DR, or CDR at the synapses we studied, anatomical studies suggest that CICR could contribute to synaptic transmission at some excitatory central synapses. Although ryanodine receptors are generally expressed at high density in dendrites and somata, they may also be present at much lower density in the presynaptic terminals of some excitatory central synapses (Kuwajima et al., 1992; Sharp et al., 1993; Furuichi et al., 1994; Ouyang et al., 1997). Ryanodine receptors are also present in boutons of inhibitory cerebellar synapses, where they contribute to presynaptic $\mathrm{Ca}$ signaling and synaptic transmission (Llano et al., 2000). In some cells the expression of ryanodine receptors may change during development. This is the case for granule cells and their associated parallel fibers in the avian cerebellum, where ryanodine receptors are only prominent in mature animals (Ouyang et al., 1997) (It has not been possible to test this in rat cerebellar slices because of the difficulty of quantifying EPSCs in mature Purkinje cells.) Thus, the possibility remains that internal Ca stores may play a role in presynaptic function at the synapses we have studied, perhaps at a different developmental stage or after trains of presynaptic activity. However, our results suggest that, in general, $\mathrm{Ca}$ influx through voltage-gated $\mathrm{Ca}$ channels provides the primary source of $\mathrm{Ca}$ responsible for the residual $\mathrm{Ca}$ signal and multiple forms of short-term presynaptic plasticity at excitatory central synapses.

\section{REFERENCES}

Alford S, Frenguelli BG, Schofield JG, Collingridge GL (1993) Characterization of $\mathrm{Ca}^{2+}$ signals induced in hippocampal CA1 neurones by the synaptic activation of NMDA receptors. J Physiol (Lond) 469:693-716.

Araque A, Sanzgiri RP, Parpura V, Haydon PG (1998) Calcium elevation in astrocytes causes an NMDA receptor-dependent increase in the frequency of miniature synaptic currents in cultured hippocampal neurons. J Neurosci 18:6822-6829.

Araque A, Carmignoto G, Haydon PG (2001) Dynamic signaling between astrocytes and neurons. Annu Rev Physiol 63:795-813.

Atluri PP, Regehr WG (1996) Determinants of the time course of facilitation at the granule cell to Purkinje cell synapse. J Neurosci 16:5661-5671.

Atluri PP, Regehr WG (1998) Delayed release of neurotransmitter from cerebellar granule cells. J Neurosci 18:8214-8227.

Barrett EF, Stevens CF (1972) The kinetics of transmitter release at the frog neuromuscular junction. J Physiol (Lond) 227:691-708.

Berridge MJ (1998) Neuronal calcium signaling. Neuron 21:13-26.

Castonguay A, Robitaille R (2001) Differential regulation of transmitter release by presynaptic and glial $\mathrm{Ca}^{2+}$ internal stores at the neuromuscular synapse. J Neurosci 21:1911-1922.

Cohen IS, Van der Kloot W (1986) Facilitation and delayed release at single frog neuromuscular junctions. J Neurosci 6:2366-2370.

Cummings DD, Wilcox KS, Dichter MA (1996) Calcium-dependent paired-pulse facilitation of miniature EPSC frequency accompanies depression of EPSCs at hippocampal synapses in culture. J Neurosci 16:5312-5323.

Dittman JS, Regehr WG (1996) Contributions of calcium-dependent and calcium-independent mechanisms to presynaptic inhibition at a cerebellar synapse. J Neurosci 16:1623-1633.

Dittman JS, Regehr WG (1998) Calcium dependence and recovery kinetics of presynaptic depression at the climbing fiber to Purkinje cell synapse. J Neurosci 18:6147-6162.

Dunlap K, Luebke JI, Turner TJ (1995) Exocytotic $\mathrm{Ca}^{2+}$ channels in mammalian central neurons. Trends Neurosci 18:89-98.

Eccles JC, Katz B, Kuffler SW (1941) Nature of the "endplate potential" in curarized muscle. J Physiol (Lond) 124:574-585.

Eccles JC, Llinas R, Sasaki K (1966) The excitatory synaptic action of climbing fibres on the Purkinje cells of the cerebellum. J Physiol (Lond) 182:268-296.

Emptage N, Bliss TV, Fine A (1999) Single synaptic events evoke NMDA receptor-mediated release of calcium from internal stores in hippocampal dendritic spines. Neuron 22:115-124.

Emptage NJ, Reid CA, Fine A (2001) Calcium stores in hippocampal synaptic boutons mediate short-term plasticity, store-operated $\mathrm{Ca}^{2+}$ entry, and spontaneous transmitter release. Neuron 29:197-208.

Feng TP (1941) Studies on the neuromuscular junction. Chin J Physiol 16:341-372.

Furuichi T, Furutama D, Hakamata Y, Nakai J, Takeshima H, Mikoshiba K (1994) Multiple types of ryanodine receptor/ $\mathrm{Ca}^{2+}$ release channels are differentially expressed in rabbit brain. J Neurosci 14:4794-4805.

Futatsugi A, Kato K, Ogura H, Li ST, Nagata E, Kuwajima G, Tanaka K, Itohara S, Mikoshiba K (1999) Facilitation of NMDAR-independent LTP and spatial learning in mutant mice lacking ryanodine receptor type 3. Neuron 24:701-713. 
Goda Y, Stevens CF (1994) Two components of transmitter release at a central synapse. Proc Natl Acad Sci USA 91:12942-12946.

Hashimoto K, Kano M (1998) Presynaptic origin of paired-pulse depression at climbing fibre-Purkinje cell synapses in the rat cerebellum. J Physiol (Lond) 506:391-405.

Haydon PG (2001) GLIA: listening and talking to the synapse. Nat Rev Neurosci 2:185-193.

Herrington J, Bookman RJ (1995) Pulse control V4.5: IGOR XOPs for patch clamp data acquisition. Miami: University of Miami.

Kamiya H, Shinozaki H, Yamamoto C (1996) Activation of metabotropic glutamate receptor type $2 / 3$ suppresses transmission at rat hippocampal mossy fibre synapses. J Physiol (Lond) 493:447-455.

Kano M, Garaschuk O, Verkhratsky A, Konnerth A (1995) Ryanodine receptor-mediated intracellular calcium release in rat cerebellar Purkinje neurones. J Physiol (Lond) 487:1-16.

Katz B, Miledi R (1967) The timing of calcium action during neuromuscular transmission. J Physiol (Lond) 189:535-544.

Katz B, Miledi R (1968) The role of calcium in neuromuscular facilitation. J Physiol (Lond) 195:481-492.

Kreitzer AC, Regehr WG (2001) Retrograde inhibition of presynaptic calcium influx by endogenous cannabinoids at excitatory synapses onto Purkinje cells. Neuron 29:717-727.

Kreitzer AC, Gee KR, Archer EA, Regehr WG (2000) Monitoring presynaptic calcium dynamics in projection fibers by in vivo loading of a novel calcium indicator. Neuron 27:25-32.

Krizaj D, Bao JX, Schmitz Y, Witkovsky P, Copenhagen DR (1999) Caffeine-sensitive calcium stores regulate synaptic transmission from retinal rod photoreceptors. J Neurosci 19:7249-7261.

Kuwajima G, Futatsugi A, Niinobe M, Nakanishi S, Mikoshiba K (1992) Two types of ryanodine receptors in mouse brain: skeletal muscle type exclusively in Purkinje cells and cardiac muscle type in various neurons. Neuron 9:1133-1142.

Llano I, DiPolo R, Marty A (1994) Calcium-induced calcium release in cerebellar Purkinje cells. Neuron 12:663-673.

Llano I, Gonzalez J, Caputo C, Lai FA, Blayney LM, Tan YP, Marty A (2000) Presynaptic calcium stores underlie large-amplitude miniature IPSCs and spontaneous calcium transients. Nat Neurosci 3:1256-1265.

Magleby KL (1987) Short-term changes in synaptic efficacy. In: Synaptic function (Edelman GM, Gall WE, Cowan WM, eds), pp 21-56. New York: Wiley.

Mintz IM, Bean BP (1993) GABA $_{B}$ receptor inhibition of P-type $\mathrm{Ca}^{2+}$ channels in central neurons. Neuron 10:889-898.

Mintz IM, Sabatini BL, Regehr WG (1995) Calcium control of transmitter release at a cerebellar synapse. Neuron 15:675-688

Mothet JP, Fossier P, Meunier FM, Stinnakre J, Tauc L, Baux G (1998) Cyclic ADP-ribose and calcium-induced calcium release regulate neurotransmitter release at a cholinergic synapse of Aplysia. J Physiol (Lond) 507:405-414.

Muschol M, Dasgupta BR, Salzberg BM (1999) Caffeine interaction with fluorescent calcium indicator dyes. Biophys J 77:577-586.

Narita K, Akita T, Osanai M, Shirasaki T, Kijima H, Kuba K (1998) A $\mathrm{Ca}^{2+}$-induced $\mathrm{Ca}^{2+}$ release mechanism involved in asynchronous exocytosis at frog motor nerve terminals. J Gen Physiol 112:593-609.

Narita K, Akita T, Hachisuka J, Huang S, Ochi K, Kuba K (2000) Functional coupling of $\mathrm{Ca}^{2+}$ channels to ryanodine receptors at presynaptic terminals. Amplification of exocytosis and plasticity. J Gen Physiol 115:519-532.

Obenaus A, Mody I, Baimbridge KG (1989) Dantrolene-Na (Dantrium) blocks induction of long-term potentiation in hippocampal slices. Neurosci Lett 98:172-178.

Ouyang Y, Martone ME, Deerinck TJ, Airey JA, Sutko JL, Ellisman MH (1997) Differential distribution and subcellular localization of ryanodine receptor isoforms in the chicken cerebellum during development. Brain Res 775:52-62.

Peng Y (1996) Ryanodine-sensitive component of calcium transients evoked by nerve firing at presynaptic nerve terminals. J Neurosci 16:6703-6712.
Rahamimoff R, Yaari Y (1973) Delayed release of transmitter at the frog neuromuscular junction. J Physiol (Lond) 228:241-257.

Regehr WG, Atluri PP (1995) Calcium transients in cerebellar granule cell presynaptic terminals. Biophys J 68:2156-2170.

Regehr WG, Stevens CF (2001) Physiology of synaptic transmission and short-term plasticity. In: Synapses (Cowan WM, Südhof TC, Stevens CF, eds), pp 135-176. Baltimore: Johns Hopkins University.

Regehr WG, Tank DW (1991) Selective fura-2 loading of presynaptic terminals and nerve cell processes by local perfusion in mammalian brain slice. J Neurosci Methods 37:111-119.

Reyes M, Stanton PK (1996) Induction of hippocampal long-term depression requires release of $\mathrm{Ca}^{2+}$ from separate presynaptic and postsynaptic intracellular stores. J Neurosci 16:5951-5960.

Reyes-Harde M, Empson R, Potter BV, Galione A, Stanton PK (1999) Evidence of a role for cyclic ADP-ribose in long-term synaptic depression in hippocampus. Proc Natl Acad Sci USA 96:4061-4066.

Sabatini BL, Regehr WG (1995) Detecting changes in calcium influx which contribute to synaptic modulation in mammalian brain slice. Neuropharmacology 34:1453-1467.

Sabatini BL, Regehr WG (1998) Optical measurement of presynaptic calcium currents. Biophys J 74:1549-1563.

Salin PA, Scanziani M, Malenka RC, Nicoll RA (1996) Distinct shortterm plasticity at two excitatory synapses in the hippocampus. Proc Natl Acad Sci USA 93:13304-13309.

Sharp AH, McPherson PS, Dawson TM, Aoki C, Campbell KP, Snyder SH (1993) Differential immunohistochemical localization of inositol 1,4,5-trisphosphate- and ryanodine-sensitive $\mathrm{Ca}^{2+}$ release channels in rat brain. J Neurosci 13:3051-3063.

Silver RA, Momiyama A, Cull-Candy SG (1998) Locus of frequencydependent depression identified with multiple-probability fluctuation analysis at rat climbing fibre-Purkinje cell synapses. J Physiol (Lond) 510:881-902.

Sitsapesan R, McGarry SJ, Williams AJ (1995) Cyclic ADP-ribose, the ryanodine receptor and $\mathrm{Ca}^{2+}$ release. Trends Pharmacol Sci 16:386-391.

Smith AB, Cunnane TC (1996) Ryanodine-sensitive calcium stores involved in neurotransmitter release from sympathetic nerve terminals of the guinea-pig. J Physiol (Lond) 497:657-664.

Treiman M, Caspersen C, Christensen SB (1998) A tool coming of age: thapsigargin as an inhibitor of sarco-endoplasmic reticulum $\mathrm{Ca}^{2+}$ ATPases. Trends Pharmacol Sci 19:131-135.

Van der Kloot W, Molgo J (1994) Quantal acetylcholine release at the vertebrate neuromuscular junction. Physiol Rev 74:899-991.

Vogt KE, Regehr WG (2001) Cholinergic modulation of excitatory synaptic transmission in the CA3 area of the hippocampus. J Neurosci 21:75-83.

Wang L-Y, Kaczmarek LK (1998) High-frequency firing helps replenish the readily releasable pool of synaptic vesicles. Nature 394:384-388.

Wang Y, Rowan MJ, Anwyl R (1997) Induction of LTD in the dentate gyrus in vitro is NMDA receptor independent, but dependent on $\mathrm{Ca}^{2+}$ influx via low-voltage-activated $\mathrm{Ca}^{2+}$ channels and release of $\mathrm{Ca}^{2+}$ from intracellular stores. J Neurophysiol 77:812-825.

Wilson RI, Nicoll RA (2001) Endogenous cannabinoids mediate retrograde signalling at hippocampal synapses. Nature 410:588-592.

Zengel JE, Magleby KL (1981) Changes in miniature endplate potential frequency during repetitive nerve stimulation in the presence of $\mathrm{Ca}^{2+}$, $\mathrm{Ba}^{2+}$, and $\mathrm{Sr}^{2+}$ at the frog neuromuscular junction. J Gen Physiol $77: 503-529$.

Zucker RS (1989) Short-term synaptic plasticity. Annu Rev Neurosci 12:13-31.

Zucker RS (1999) Calcium- and activity-dependent synaptic plasticity. Curr Opin Neurobiol 9:305-313.

Zucker RS, Lara-Estrella LO (1983) Post-tetanic decay of evoked and spontaneous transmitter release and a residual-calcium model of synaptic facilitation at crayfish neuromuscular junctions. J Gen Physiol $81: 355-372$ 